University of Nebraska - Lincoln

DigitalCommons@University of Nebraska - Lincoln

Publications from USDA-ARS / UNL Faculty

U.S. Department of Agriculture: Agricultural

Research Service, Lincoln, Nebraska

2008

Social and Economic Aspects of Areawide Pest Management

Sean P. Keenan

Oklahoma State University

Paul A. Burgener

University of Nebraska-Lincoln, pburgener2@unl.edu

Follow this and additional works at: https://digitalcommons.unl.edu/usdaarsfacpub

Part of the Agricultural Science Commons

Keenan, Sean P. and Burgener, Paul A., "Social and Economic Aspects of Areawide Pest Management" (2008). Publications from USDA-ARS / UNL Faculty. 649.

https://digitalcommons.unl.edu/usdaarsfacpub/649

This Article is brought to you for free and open access by the U.S. Department of Agriculture: Agricultural Research Service, Lincoln, Nebraska at DigitalCommons@University of Nebraska - Lincoln. It has been accepted for inclusion in Publications from USDA-ARS / UNL Faculty by an authorized administrator of DigitalCommons@University of Nebraska - Lincoln. 


\title{
Social and Economic Aspects of Areawide Pest Management
}

\author{
Sean P. Keenan ${ }^{1}$ and Paul A. Burgener ${ }^{2}$ \\ ${ }^{1}$ Department of Entomology and Plant Pathology, Oklahoma State \\ University, Stillwater, Oklahoma, USA \\ ${ }^{2}$ Department of Agricultural Economics, Panhandle Research and \\ Extension Center, University of Nebraska-Lincoln, Scottsbluff, Nebraska, \\ USA.
}

\section{Introduction}

Areawide pest management (AWPM) programmes build upon past achievements in agricultural innovation, expanding the implementation of integrated pest management (IPM) practices to larger geographical scales (Kipling, 1980; Kogan, 1998). Implementation on a broad geographical scale means that social, institutional and financial capital must be dedicated to the task:

Social, political, and economic factors must come together with science before an areawide program can succeed. In addition, scientific challenges include defining the appropriate geographical area, selecting the control approaches to test and combine, and addressing the different life cycles of the target pest as well as secondary pests.

(Faust, 2001)

Because AWPM programmes have typically relied upon voluntary adoption, pest management practices must demonstrate economic advantage to farmers over their existing practices. Adoption will also be facilitated if AWPM practices have low complexity, ease of trial adoption, rapidly observable results and high compatibility with other aspects of farm management (see Rogers, 2003).

This chapter explores demonstration elements from the US Department of Agriculture, Agricultural Research Service's demonstration programme for cereal aphid AWPM. We explore elements of the demonstration programme as agricultural innovations. We discuss potential adoption of these elements by wheat producers on the Great Plains and implications of the programme outcomes for other wheat-growing regions of the world. We begin with a history of research on the adoption of agricultural innovations, which provides the context for evaluating the cereal aphid programme from the perspective of farmer adoption. Chapter 19, this volume, by

(c) $\mathrm{CAB}$ International 2008. Areawide Pest Management: Theory and 
Kristopher Giles et al. provides a summary and assessment of the research and technological developments of the cereal aphid AWPM programme.

\section{Adoption of Agricultural Innovations}

The social and economic challenges confronting AWPM are the same as those confronted by promoters of past agricultural innovations. An innovation may be any idea, practice or object whose adoption is 'new' to a group of potential adopters (Rogers, 2003). That is, application of the innovation can be 'new' even if the innovation itself is not new. Innovation is a social process that occurs when there is increasing interest (public awareness/discussion) in some form of technology and a concerted effort to encourage adoption (new programmes, new organizations, etc.). So, for example, while aphid-resistant wheat varieties have been available to wheat producers for a significant period, the promotion of resistant cultivars as part of a comprehensive AWPM programme can be innovative.

First published in 1962, Diffusion of Innovations by Everett Rogers brought together ideas developed by rural sociologists in an effort to characterize and improve the diffusion of agricultural innovations. An influential study that launched this effort was an effort to promote the adoption of hybrid seed maize in Iowa (Ryan and Gross, 1943). Core aspects of the innovation-diffusion model developed through an 'invisible college' of rural sociologists interested in assisting cooperative extension with the diffusion of agricultural innovations (see North Central Rural Sociology Committee, 1955; Fliegel with Korsching, 2001; Rogers, 2003). The history of this literature was summarized in Diffusion Research in Rural Sociology by Frederick Fliegel (first published in 1993 by Greenwood Press and then in 2001 by the Social Ecology Press, with an additional chapter by Peter Korsching).

Attention of rural sociologists in the USA turned toward the international context in the 1960s (Rogers, 2003). The innovation diffusion concept proved useful in describing how new technologies spread in developing nations. The title of the second edition of Rogers' book, Communication of Innovations: a Cross-Cultural Approach, reflected this international perspective (Rogers with Shoemaker, 1971). As diffusion research became global, a broad research literature developed around the problem of distinguishing when innovations were more likely to succeed. Subjects of study included education, nutrition, family planning, health and medicine. Following this burst of interest in international topics, the study of diffusion became more closely associated with the developing fields of mass communication and marketing (Rogers, 2003).

\section{Fundamental concepts of innovation diffusion}

In Diffusion of Innovations, Rogers (2003) summarizes four main elements that are useful for distinguishing successful from unsuccessful innovations. The first is concerned with characteristics of the innovation itself, which make it more or less attractive to potential adopters. The other three elements are concerned with the social context of diffusionthese are the communication process, the temporal process and the social networks of diffusion. 


\section{Characteristics of the innovation}

The study of innovation diffusion begins with the characteristics of the innovation. Rogers (2003) summarized five characteristics of innovations:

- The concept of relative advantage is meant to encompass social, economic and technical attributes of an innovation, but the concern is with the experience of early adopters and the perception of potential adopters who observe the experience of early adopters.

- Compatibility is likewise meant to encompass socio-economic attributes as well as technical compatibility with other practices. To what extent is the innovation compatible with existing practices that will not change with adoption of the innovation?

- Trial adoption refers to the degree to which an innovation may be tested by a potential adopter on a limited basis prior to adopting it fully.

- Observable results refer to the degree to which favourable results of adopting the innovation may be seen early in the adoption process.

- Complexity means that innovations will be less likely to diffuse rapidly if they are technically complex, difficult to integrate with other practices or require extensive learning or practice to use. As with the other four characteristics, complexity is concerned with the perceptions/experiences of potential adopters as well as the technological aspects of complexity.

\section{The communication process}

Regarding communication channels, some potential adopters will learn about a given innovation through mass media channels, while others will learn about it through interpersonal channels (Rogers, 2003). Additional information about the innovation (technical aspects, testimonials, meetings, new organizations, etc.) may be obtained through either or both of these channels. Naturally, mass media channels have the potential to reach the largest number of people quickly, while interpersonal channels may have greater influence on the adoption decision, particularly for individuals who have little trust and/or less access to mass media channels. When implementing programmes like AWPM, it is important to bear in mind that individuals will differ in terms of both their access to and their preference for communication channels.

\section{The temporal process}

In terms of the temporal process, some innovations are quickly adopted while others require a significant period before the innovation achieves 'take-off' (innovations that never 'take off' are characterized as 'failed innovations' after interest in them wanes). Graphically represented, the cumulative percentage of persons adopting a successful innovation over time will be represented by some form of an S-shaped curve (see Fig. 6.1). The take-off stage is closely related to the social networks of diffusion, as discussed below.

Related to the temporal process, innovation researchers have summarized characteristics of the innovation-decision process and characteristics describing the relative innovativeness of potential adopters (North Central Rural Sociology Committee 1955; Rogers 2003). With respect to the decision process, there is a logical progression of 


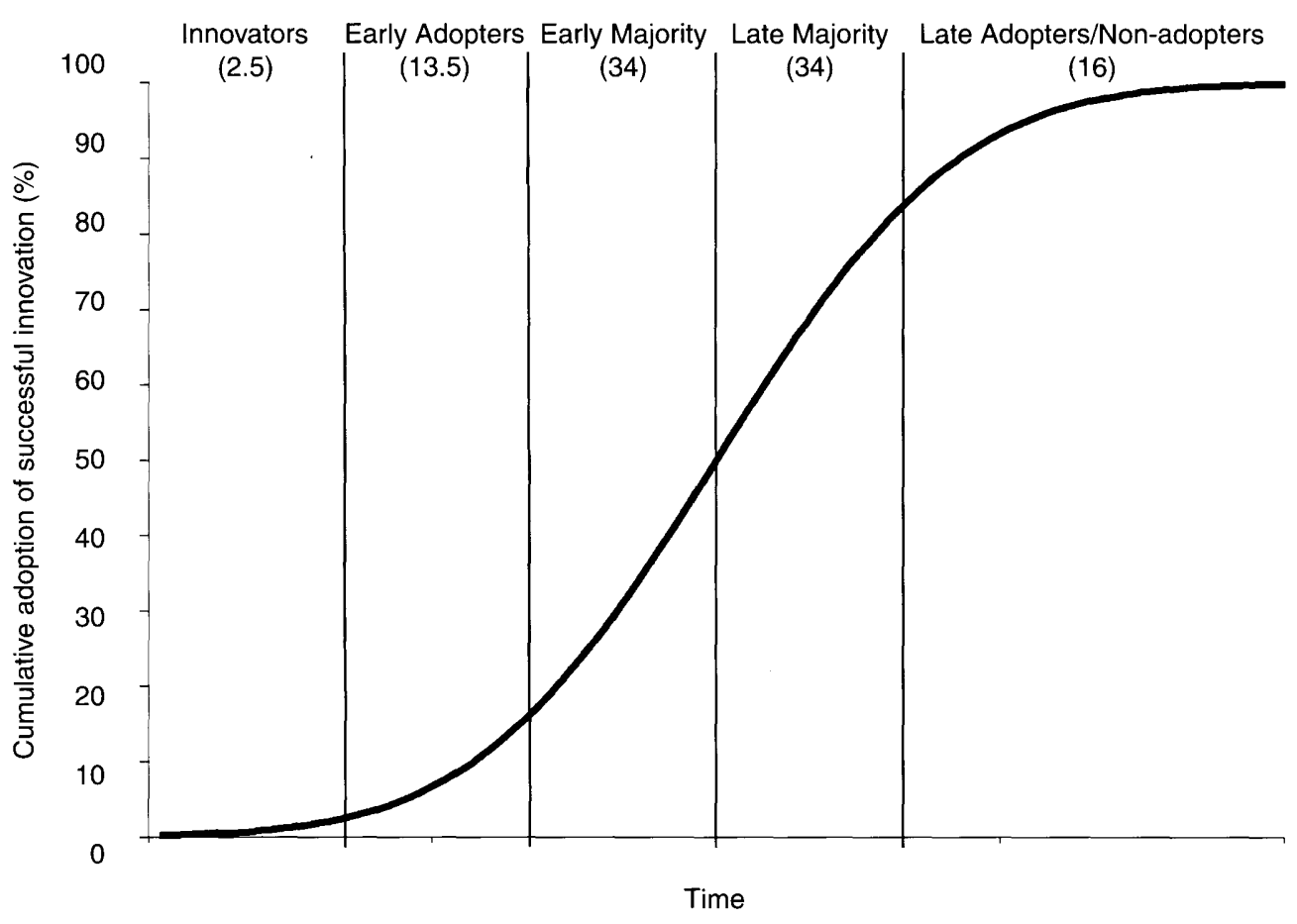

Fig. 6.1. Diffusion curve and adopter categories (adapted from similar illustrations by North Central Rural Sociology Committee 1955; Dent, 1999; Rogers, 2003; Fuchs 2007).

events that influences the rate of innovation adoption. Potential adopters must first become aware of an innovation, form a positive or negative attitude toward it, make a decision to adopt or not adopt, then implement its use and, finally, evaluate the results. Bennett (1977) represented a similar decision process with the acronym, KASA: Knowledge, Attitude, Skills and Aspirations. Regardless of the temporal sequence or rapidity with which potential adopters acquire these attributes, all four are necessary for innovation adoption.

The relative innovativeness of potential adopters means that early adopters may be qualitatively different from later adopters of innovations, as illustrated in Fig. 6.1. In general, earlier adopters have higher education, more access/use of mass media communication channels and greater technical competence than later adopters. Rogers (2003) summarized five categories of potential adopters in terms of their relative innovativeness: innovators, early adopters, early majority, late majority and late adopters, or laggards (see also North Central Rural Sociology Committee, 1955). Individuals in these categories are presumed to share qualitative attributes that dispose them to be either earlier or later adopters of innovations; hence, the categories are related to zones of the S-shaped adoption curve.

As summarized in Table 6.1, innovators are viewed by peers as venturesome; by nature they are a small minority of the group of potential adopters. They are willing to experiment with new innovations and thus serve as gatekeepers for innovations - 
Table 6.1. Adopter categories in terms of how individuals in these categories are viewed by peers (potential adopters) and roles they play in the innovation diffusion process (adapted from information in North Central Rural Sociology Committee, 1955; Rogers, 2003).

\begin{tabular}{lll}
\hline Adopter category & Peer view (reputation) & Role in diffusion \\
\hline Innovator & Venturesome & Gatekeeper \\
Early adopter & Respected & Community opinion leader \\
Early majority & Deliberate & Local adoption leader \\
Late majority & Sceptical & Acceptance \\
Late adopter/non-adopter & Traditional & Confirmation, preservation \\
\hline
\end{tabular}

they are the first to see success with beneficial innovations, but few will follow their lead. Of those who will, many are community leaders that have broad social ties and keep abreast of developments in their field/industry. Because they tend to be well known and respected, community leaders can facilitate the 'take-off' stage of an innovation (in Fig. 6.1, take-off occurs when the rate of adoption first increases to its highest rate, or at the beginning of the steepest part of the curve).

Early majority adopters are locally significant leaders who are more deliberate in their practices and decisions as compared with innovators and community leaders. They pay close attention to community leaders and have many local ties as well (where local may refer to geographical and/or social network proximity). Consequently, these individuals play a key role in the successful diffusion of innovations.

Late majority adopters are similar to early majority adopters except that they are more sceptical and have fewer social ties. What distinguishes the late majority is that they adopt an innovation at a time when it is transforming from an innovation to an accepted (normative) practice. Late adopters and non-adopters are individuals who, for various reasons, are either resistant to an innovation or do not perceive it to be useful to their situation. They are viewed by peers as traditional, or dedicated to older ways of doing things.

\section{Social networks}

It is apparent from these characteristics that social ties between potential adopters can have a significant influence on the success or failure of innovation diffusion. Besides the interrelations of potential adopters, other characteristics of social networks may influence the relative success of innovation diffusion. Rogers discussed the importance of communication network characteristics, opinion leadership, social ties (links) and the point of critical mass (take-off) as influences on the rate of innovation diffusion. Rogers used the example of the Cooperative Extension System as an illustration of a successful innovation-diffusion network (Rogers, 2003). The Extension System illustrates successful technology transfer, combined use of mass media and interpersonal communication channels, and strategies for overcoming heterophily differing degrees and types of technical competence - between change agents and potential adopters. 


\section{Alternatives to (or expansions on) the innovation diffusion model}

Some scholars have encouraged extension leaders to adopt a different framework than the innovation diffusion model, favouring other models of social networks such as social learning theory and actor-network theory (see Coughenour and Chamala, 2000; Coughenour, 2003; Leeuwis and van den Ban, 2004). Leeuwis and van den Ban argued that the new model for extension should be one of facilitation and communication (social learning) rather than technology transfer of singular innovations. The innovation diffusion model categorized potential adopters with the assumption that everyone is, or needs to be, moving in the same direction. In practice, extension professionals understand that innovation occurs through unplanned change, informal networking and conflict. Thus, Leeuwis and van den Ban (2004) argued, designers of extension should build programmes that help farmers develop and reinvent technologies and social relationships instead of simply adopting uniform technological innovations from university-sponsored research. Consistent with this view, Coughenour (2003) observed that the development of conservation tillage in Kentucky involved broad changes in farming practices and a cooperative reinvention process that required the participation of broader social networks encompassing private companies, farmers' organizations and cooperative extension.

\section{Diffusion of IPM}

Sociologists and extension professionals have applied the concepts of innovation diffusion to the implementation of IPM technologies (Buttel et al., 1990; Ridgley and Brush, 1992; Bechinski, 1994; Cuperus and Berberet, 1994; Nowak et al., 1996; Cuperus et al., 2000). Fuchs (2007) described the importance of change agents and 'reinvention' of IPM innovations for commercial agriculture. IPM has been similar to other forms of system-level agricultural change in that change agents have included a broader range of participants than just extension professionals. IPM has involved scientists from governmental, non-governmental and for-profit organizations. The high level of technical competence of these change agents suggests that a challenge of IPM is a high degree of heterophily with potential adopters (i.e. greater technical competence of change agents versus potential adopters - the farmers). Fuchs notes that IPM programmes have tried to overcome this by involving extension professionals in adaptive research programmes; this facilitated ongoing reinvention efforts and greater collaboration with the end users.

Petrzelka et al. (1997) identified a range of challenges in implementing an integrated crop management programme in Iowa, particularly the difficulty of illustrating successful results and profitability advantages early enough in the programme to maintain producer interest. Petrzelka et al. (1997) also discussed the importance of producers' trust in programme proponents as an important factor in successful programme implementation. Similarly, Baumgärtner et al. (2007) described how institutional structures and adaptive management are important to the design and implementation of IPM programmes (see also Dent, 1995; Kogan et al., 1999; Baumgärtner et al., 2003). 
Following in this vein, areawide pest management programmes supported by the US Department of Agriculture, Agricultural Research Service (USDA-ARS) made significant efforts to use a cooperative, team-building approach. Essential features of areawide pest management are implementation of control tactics over large geographical areas, coordination (development of social networks) among diverse organizations within these geographical areas and a focus on reducing pest populations to an acceptably low density (Chandler and Faust, 1998). Many of the chapters of this book discuss the relative successes of areawide programmes in their efforts to involve change agents and agricultural producers in the implementation of AWPM.

\section{Winter Wheat and Areawide Pest Management for Cereal Aphids}

Wheat remains a key food grain throughout the world. Wheat production can be found in all of the agricultural production regions, with major production areas located in the semi-arid regions of Asia, Europe, North America, South America, Africa and Australia. World wheat production is near 600 million $\mathrm{t}$ on an annual basis. The USA contributes nearly $10 \%$ of this production, approximately 60 million $t$ annually. Of the USA production, nearly half, or 25 million $t$, is hard winter wheat, which is primarily produced in the Great Plains states of Texas, Oklahoma, Kansas, Colorado, Wyoming and Nebraska. Much of this production is on millions of dryland production acres that produce less than 60 bushels per acre annually, and a large percentage is in a wheat-fallow system that splits these low yields into production on a semi-annual basis.

Though each of these production areas has its own specific insect pest concerns, aphid pests can be found in all of these critical production areas. For winter wheat producers in the Great Plains of the USA, the Russian wheat aphid, Diuraphis noxia (Mordvilko) and the greenbug, Schizaphis graminum (Rondani) are the major aphid pests. The Russian wheat aphid (RWA) has caused in excess of US $\$ 1.2$ billion in losses to the wheat and barley industries since its appearance in 1986. Annual greenbug losses have been estimated as high as US $\$ 400$ million, depending on the year. Presently, the control of RWA and greenbug is nearly all through chemical insecticides, and losses from annual infestations of these pests can be attributed in a large part to the cost of insecticide control. For many winter wheat producers in the Great Plains, the cost of treatment may be excessive. These dryland wheat producers base their profitability on low-cost and low-input production systems. Therefore, wheat producers need to use alternative IPM strategies to control insects across a wide area.

In autumn 2001, USDA-ARS initiated a 5-year areawide demonstration programme for suppression of RWA and greenbug. A cooperative research team was assembled from five universities - the University of Nebraska, Colorado State University, Kansas State University, Oklahoma State University and Texas A \& M University. The research team worked with USDA-ARS to establish cooperative relationships with wheat producers and field demonstration sites.

The area of concern for RWA and greenbug is vast, encompassing the majority of the area of the US Great Plains where winter wheat is grown. The RWA and greenbug areas depicted in Fig. 6.2 span portions of six states and stretch 


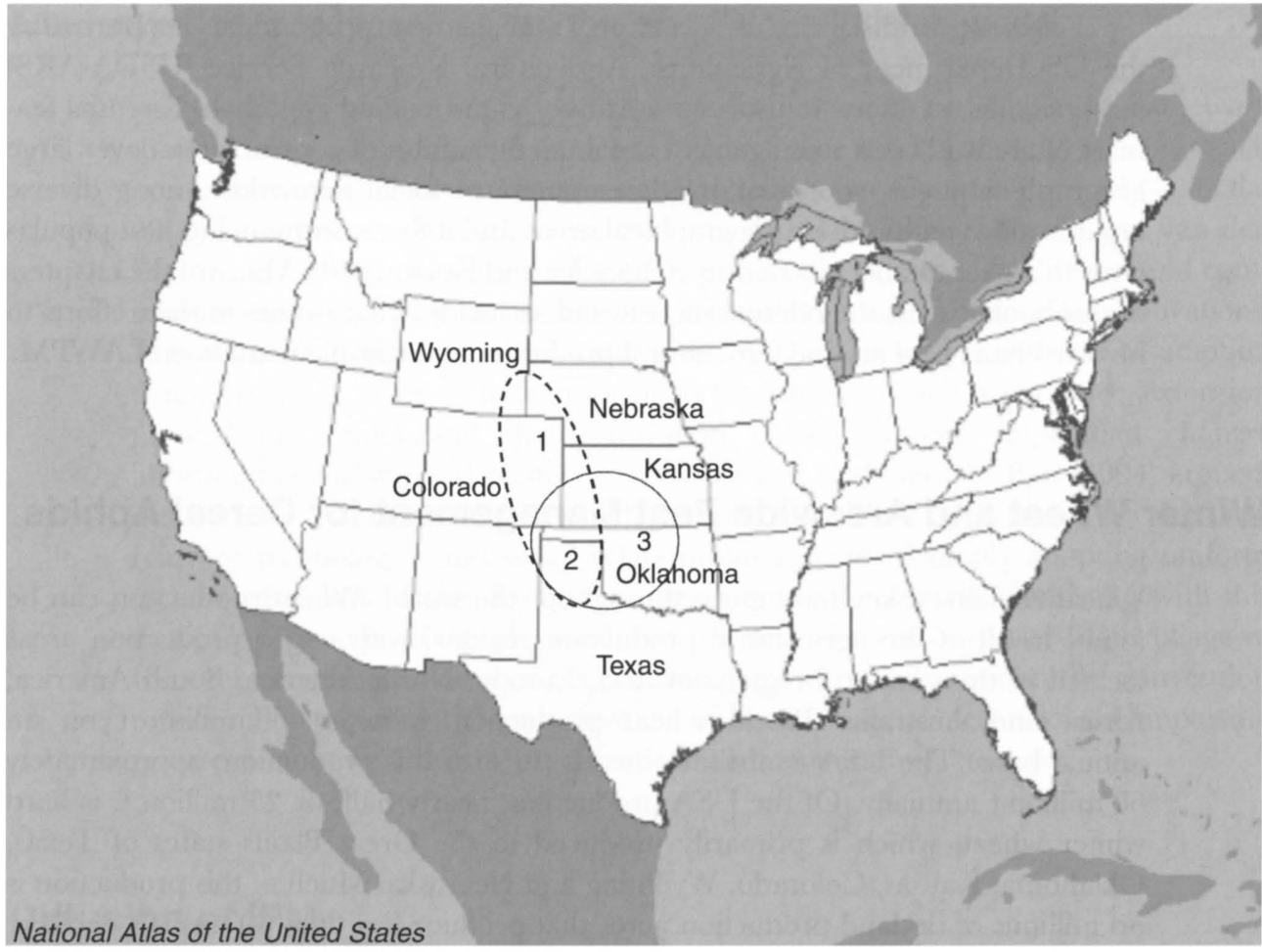

Fig. 6.2. Map showing the three zones of the cereal aphid areawide programme; the dashed ellipse indicates areas of Russian wheat aphid (RWA) concern and the solid ellipse indicates areas of greenbug concern.

approximately 600 miles $(375 \mathrm{~km})$ north-south and 400 miles $(250 \mathrm{~km})$ east-west. The areawide programme focused on working with a series of demonstration field sites and a small group of participating wheat producers recruited from within the three zones identified in Fig. 6.2: a northern area (Zone 1), where RWA is the primary insect pest; a south-western area (Zone 2), which is concerned about both RWA and greenbug; and a south-eastern area (Zone 3), where the greenbug is the major aphid pest.

\section{Farm operator participation}

A total of 141 producers participated in the project for the entire 4-year demonstration phase of the programme. As noted in Table 6.2 each zone was well represented, with 45 growers in Zone 1, 42 in Zone 2 and 54 in Zone 3. The average age of the producers was 48.9 years in 2003, with little difference across the three zones. Participating growers closely reflect the average age of farmers in the region, being slightly younger than the 52 years of average age for all farmers. The youngest producer in the project was 22 years of age, while the oldest was 76 . 
Table 6.2. Characteristics of farm operators participating in the areawide programme, 2003.

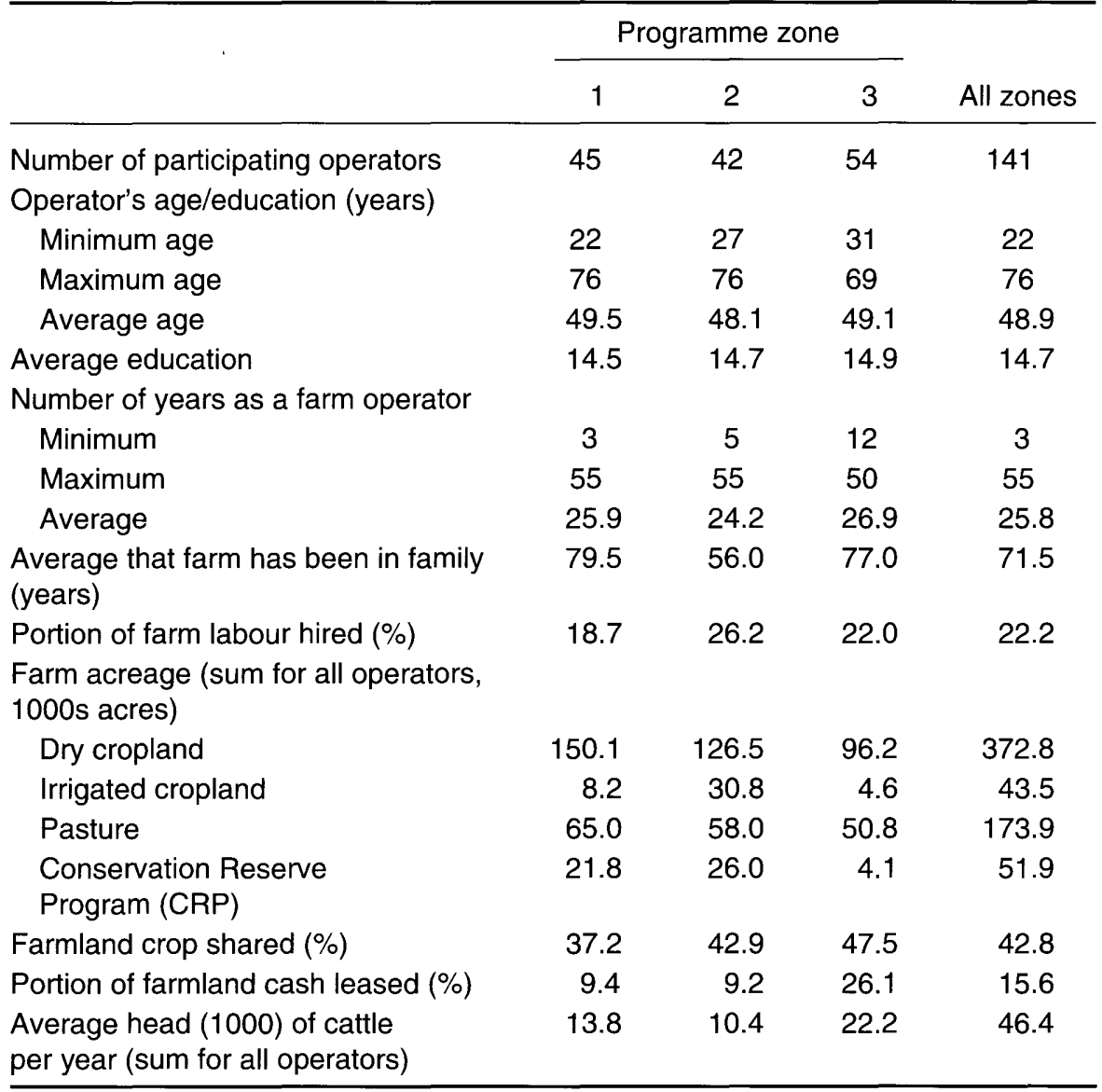

Education and farm experience were also similar across each of the zones. The education level averaged 14.7 years for all 141 growers. Producers involved in the programme averaged 25.8 years of experience, ranging from 3 years to 55 years. Some of these farms had been in the same family for more than 75 years. The farms were family-based operations with less than $25 \%$ of the labour being hired on average.

The farms in this programme managed 372,800 acres (151,000 ha) of dryland crops, 43,500 acres (17,600 ha) of irrigated crops, 173,900 acres (70,400 ha) of pasture and included 52,000 acres (21,100 ha) of Conservation Reserve Program (CRP) participation. Over $50 \%$ of the farmland acres were leased, not unlike the general farm population in the region. Of the leased acres, the amount share leased is nearly $75 \%$.

The demographics of the producers in this project were similar to the averages for the region, providing a representative group for acquiring information about farming practices in the region. Based on these characteristics and information gleaned from interactions in focus groups, it was evident that several of the key programme participants were early innovators and community leaders, while most of 
the remaining producers could be classified as early majority adopters. These individuals were helpful in evaluating programme elements and, at a later point in time, would be critical in increasing the rate of adoption by peers.

Annual cost-of-production interviews with participating wheat growers provided information on farm operating costs and revenues. Focus groups with producers at the beginning and end of the demonstration programme were a way of initiating relationships with producers while learning about their farming history and decision making (Keenan et al., 2007a, b). The plan for the demonstration phase was to observe growers' practices without significant intervention in their farming practices. However, the programme did have some interventions. Operators with demonstration fields were provided with an aphid-resistant seed variety where appropriate to their location. This allowed the areawide research team to evaluate the effectiveness of the resistant variety. Also, focus groups provided an opportunity for operators to learn from one another, and educational materials (newsletters, information on field scouting methods) did provide operators with information about the programme elements.

The strategy of the demonstration was to enhance the effectiveness of biological control with diversified cropping and, where appropriate, the use of cultivars resistant to RWA or greenbug. In this context, increased use of simplified field scouting methods by farm operators would help reduce use of insecticide treatments; field scouting would also help farm operators to monitor the effectiveness of biological control. Additionally, the programme was an opportunity to advance remote sensing and information technology (IT) applications for areawide pest management implementation.

\section{Aphid-resistant cultivars}

In general, RWA-resistant varieties are most adapted for use in eastern Colorado, with many of the varieties developed through Colorado State University. The greenbugresistant variety, TAM 110, is most adapted for use in the Texas Panhandle. Programme participants reflected these characteristics in the use of these wheat varieties. Table 6.3 summarizes the use of resistant wheat varieties among programme participants. Some producers in Zones 1 and 2 had been using RWA-resistant varieties since these varieties first became available. In Zone 1 (mostly in Northern Colorado), $14.7-19.2 \%$ of annual wheat acres planted by programme participants were a RWA-resistant variety. Use was more common among Zone 2 producers (mostly in south-eastern Colorado), where between 19.1 and $25.2 \%$ of programme participants' annual wheat acres were in a RWA-resistant variety.

Resistant cultivars of wheat seed have been used for the past decade in the RWA areas of Colorado, Kansas, Wyoming and Nebraska. These cultivars have helped farmers produce winter wheat in the region without having to treat with chemical pesticides. The genetic resistance was bred into several cultivars that have allowed producers to use the resistant technology in most of the production areas across the region. These resistant cultivars had significant success until an additional RWA biotype was discovered in the region that is not affected by the resistance in the existing cultivars. 
Table 6.3. Acres of all wheat varieties (summed for 141 programme participants) and percentage of acres in Russian wheat aphid (RWA) and greenbug-resistant varieties by programme zone and year.

\begin{tabular}{|c|c|c|c|c|}
\hline \multirow[t]{2}{*}{. } & \multicolumn{4}{|c|}{ Crop year } \\
\hline & 2002 & 2003 & 2004 & 2005 \\
\hline \multicolumn{5}{|l|}{ Zone 1} \\
\hline Sum of wheat acreage ${ }^{a}$ & 56,015 & 56,669 & 54,453 & 63,253 \\
\hline RWA resistant $(\%)^{\mathrm{b}}$ & 19.2 & 18.3 & 14.7 & 18.2 \\
\hline Greenbug resistant (\%)c & 2.5 & 7.8 & 9.6 & 7.2 \\
\hline \multicolumn{5}{|l|}{ Zone 2} \\
\hline Sum of wheat acreage ${ }^{a}$ & 62,404 & 78,788 & 65,236 & 73,298 \\
\hline RWA resistant $(\%)^{\mathrm{b}}$ & 24.7 & 25.2 & 19.1 & 21.2 \\
\hline Greenbug resistant (\%) ${ }^{d}$ & 13.9 & 18.5 & 26.4 & 13.6 \\
\hline \multicolumn{5}{|l|}{ Zone 3} \\
\hline Sum of wheat acreage ${ }^{a}$ & 65,789 & 67,745 & 71,900 & 72,145 \\
\hline RWA resistant (\%) & - & - & - & - \\
\hline Greenbug resistant (\%) & - & - & - & - \\
\hline
\end{tabular}

aSummed acreage for known wheat varieties for all 141 programme-participating producers. bRussian wheat aphid-resistant wheat varieties were: Halt, Prairie Red, Prowers 99, Yumar, Ankor and Stanton.

cWheat varieties Above and AP502CL.

dWheat variety TAM 110.

New research is under way to provide additional resistant cultivars that will have resistance to all of the different RWA biotypes. While producers used this technology, it was not intended for all of the cereal area on the farm. It was expected that farmers would use resistant cultivars on a portion of their acres, the most susceptible to RWA attack, and use other non-resistant varieties on the remainder of the acres. With the discovery of new RWA biotypes, the sowing of resistant cultivars has been reduced, but not eliminated. Producers in high RWA pressure areas continue to use these cultivars to reduce the presence of the initial biotype, with the understanding that recently discovered biotypes will remain in the wheat. If resistant cultivars can reduce pressure to levels that are below the economic damage threshold for treatment, there is a positive response from the use of resistant cultivars.

The proportion of Zone 2 wheat acres that were planted with TAM 110 varied between 13.6 and $26.4 \%$ of the acres planted by programme participants. In focus groups, several producers indicated that they liked the greenbug resistance trait of TAM 110, but many indicated that traits for disease resistance, drought resistance, yield potential and forage potential were bigger considerations in their variety selection decision.

In addition to TAM 110, the varieties Above and AP502CL are greenbug resistant. TAM 110 was used by some of the Zone 2 producers (primarily among those in the Panhandle region of Texas). Above and AP502CL were mostly grown by Zone 1 producers, with the proportion of acres in these varieties varying from 2.5 to 
9.6\% annually among all programme participants. However, focus group discussions suggested that producers were more likely to be growing these varieties for weed management benefits or for sale as seed wheat rather than for the benefits of greenbug resistance. TAM 110 is widely used to assist producers in managing greenbug pressures, but this cultivar has its own set of drawbacks. In recent years, there has been significant rust pressure in the southern wheat-growing areas, forcing producers to manage for multiple pest pressures in the same region. TAM 110 is susceptible to rust, which forces wheat producers to take a decision on the risk factors between rust pressure and greenbug pressure.

Plant breeders continue to work on solutions to these problems, while attempting to maintain yield and quality characteristics necessary for new cultivars to be accepted by farmers. Aphid-resistant cultivars are generally not adapted to Zone 3, and none of the programme participants in that zone indicated growing resistant varieties.

\section{Field scouting}

Field scouting is critical to the successful control of insect pests in these areas. While field scouting may be critical, many producers do not spend an adequate amount of time and effort on this management strategy. Although the need for field scouting can be easily quantified for producers, the critical times for scouting are also very busy times for many producers and the scouting gets pre-empted by other critical crop production tasks. There are crop consultants in the area that could be hired to complete this task, but the cost is high for these services and wheat is a low-cost, low-input system, as noted previously. Another factor that limits the amount of scouting done by wheat producers is the size of their farms. Many wheat farmers produce more than 2000 acres (800 ha) of wheat each year. The size of the farm limits the ability of the farmer to adequately scout all of the acres for insect, disease and weed pests.

A simplified method of field scouting has been recently modified to incorporate natural enemy identification (Elliott et al., 2004; Royer et al., 2005a, b). This system, referred to as Glance ' $\mathcal{N}$ Go, has made a significant effort to increase the rate of adoption by farmers by improving upon the characteristics of field scouting as an agricultural innovation: relative advantage, compatibility, trial adoption, observable results and complexity (see Cuperus and Berberet, 1994).

Table 6.4 summarizes dryland wheat field scouting practices indicated by areawide programme participants at the beginning of the programme. Overall, $29.8 \%$ indicated that they did not practise any field scouting of dryland wheat, and another $29.1 \%$ relied on a private crop consultant or other crop advisor (including cooperative extension educators) to scout wheat. Of those who did their own field scouting, 36.9\% indicated that they had scouted irregularly or infrequently (e.g. only when they had heard about an aphid outbreak in their area), and only $4.3 \%$ indicated that they had scouted at regular intervals for preventive purposes. By project zone, a slightly higher percentage of programme participants in Zone 3 indicated that they had scouted regularly, 7.4\%, compared with Zones $2(2.4 \%)$ and $1(2.2 \%)$. Zone 2 producers were the most likely to use a crop consultant or crop advisor 
Table 6.4. Field scouting methods as indicated by wheat producers by areawide programme zone (2003).

\begin{tabular}{lccrrr}
\hline & \multicolumn{3}{c}{$\begin{array}{c}\text { Percentages within } \\
\text { programme zones }\end{array}$} & \\
\cline { 2 - 4 } Field scouting carried out by: & 1 & 2 & 3 & All zones \\
\hline Crop consultant or crop advisor & 15.6 & 42.9 & 29.6 & 29.1 \\
Self, infrequently or irregularly & 35.6 & 23.8 & 48.2 & 36.9 \\
Self, regular interval & 2.2 & 2.4 & 7.4 & 4.3 \\
None & 46.7 & 31.0 & 14.8 & 29.8 \\
Percentage totals & 100.0 & 100.0 & 100.0 & 100.0 \\
Total number of producers & 45 & 42 & 54 & 141 \\
\hline
\end{tabular}

$(42.9 \%)$. Zone 1 producers were most likely to do no scouting at all $(46.7 \%)$ or to scout infrequently or irregularly $(35.6 \%)$.

Focus groups with programme participants helped to reveal some of the characteristics of producers who had frequently scouted. In the case of Zone 3, many of the producers who had scouted at regular intervals were concentrated in an area of more frequent greenbug outbreaks. Some of these producers were also more likely to have smaller acreages of wheat and to be intensive farm managers (attention to detail). They were also in an area where cooperative extension educators had made significant efforts to inform producers of greenbug problems and IPM methods including field scouting. Focus groups also suggested that programme participants in Zone 3 were more familiar with the Glance ' $\mathcal{N}$ ' $G 0$ field scouting system at the end of the demonstration programme than they were at the initiation of the programme. In particular, more participants indicated that they had scouted for the presence of beneficial insects as well as aphids since they had become aware of the Glance $\mathcal{N}^{\prime}$ Go system. In the second-round focus groups with programme participants in Zones 1 and 2, most had become aware of the discovery of the Russian wheat aphid biotype 2 during the programme, and some had increased their field scouting efforts as a result.

\section{Diversified dryland cropping}

Recently, Great Plains dryland crop production systems have moved toward less tillage and more intensive cropping. Increases in acres of dryland maize, grain sorghum, sunflowers, proso millet, cotton and other alternative crops reinforce this observation. As traditional wheat producers look for options to increase profits, lower risk and mitigate pest losses, they have looked to the potential for additional crop diversity. The nature of these new production systems has made it necessary to move toward limited tillage in conjunction with the move to diversified cropping systems. Diversifying crops in the rotation minimized annual yield variability (Anderson et al., 1999). This statement, while simple and short, may be the key to 
producers considering changes in the Great Plains production system. If long-term yield variability can be reduced, the profitability from year to year will also increase.

The major pest problem for monoculture wheat systems in the Great Plains is the presence of winter annual grasses (downy brome, jointed goatgrass, feral rye) in the winter wheat crop. Diverse cropping systems can effectively control winter annual grasses in winter wheat systems, allowing wheat producers to deliver a higher-yielding crop that meets quality guidelines (Daugovish et al., 1999). Typically, producers make the move toward crop diversity to control weed or insect pests in the system more often than to increase profits. Pest issues may be so severe that the only option is to move to another crop. In these cases, profitability may have suffered significantly enough that there is increased profitability from diversity by default.

Several recent studies have looked at the profitability of diversified crop rotations across the Great Plains. Dhuyvetter et al. (1996) determined that profitability of diverse systems with a crop grown on $67-75 \%$ of the acres was higher than in the traditional wheat-fallow system in eight of the nine locations in studies from North Dakota to Texas. In this study, tillage systems were also evaluated for profitability in different cropping systems. For the wheat-fallow system, no-till systems were never more profitable than either conventional or reduced tillage systems. However, in the more intensive systems, no-till or reduced tillage was always more profitable than the conventional tillage system. Given these results, the change to diverse cropping systems seems to be most successful when combined with a change in tillage systems. Kaan et al. (2002) showed that diverse systems in Eastern Colorado were more profitable than wheat-fallow over several years. These results were based on a set of studies at two sites in Colorado that represented two of the zones in the areawide project.

When diverse production systems are adopted to assist with control of either insect or weed pests, producers may not need the system to show significantly high profit levels. The farm may actually be better off if the diversified system is equally as profitable as the monoculture system, while providing pest management benefits to the entire farm. Another potential benefit is the opportunity to reduce risk in these highly risky areas. Production of several crops will allow the farmer to produce crops that enter into different markets, grow during different seasons and utilize different sets of resources. Hail and drought are key weather risks throughout this area and, by growing different crops, a producer may be able to spread the risk of both hail and drought. Markets for different crops and types of crops may not move in similar directions on a yearly basis, allowing the farm to capture profits in one market in a year when another market may be soft.

For evaluating the relative advantage of crop diversity, Table 6.5 summarizes annual averages from 4 years of net returns to land and management (in US dollars) for producers participating in the AWPM demonstration programme. (In the context of this project, net return to land and management is defined as return prior to any charges for land or management for the farm producer.) Differences in per-acre returns by zone illustrate the advantages of climate and rainfall from the north-west to south-east regions of the central US Great Plains. The overall average net return for Zone 1 producers was US $\$ 23.35$ per acre $(0.4 \mathrm{ha})$ compared with US $\$ 39.18$ for Zone 2 and US $\$ 70.78$ for Zone 3 producers. This is related to the acres farmed, illustrated earlier in Table 6.2, producers in Zones 1 and 2 typically farm larger acreages than producers in Zone 3, somewhat levelling the differences in overall economic returns to the whole farm. 
Table 6.5. Dryland crop diversity and net return per acre summary by programme zone and crop categories.

\begin{tabular}{lcccc}
\hline \multirow{2}{*}{$\begin{array}{l}\text { Average returns to land and } \\
\text { management (US\$), 2002-2005 } \\
\text { by project zone and crop }\end{array}$} & \multicolumn{4}{c}{ Crop diversity } \\
\cline { 2 - 5 } & Low & Medium & High & All producers \\
\hline Zone 1 (all dryland crops) & 24.58 & 23.51 & 22.15 & 23.35 \\
Wheat-fallow & 24.17 & 21.51 & 24.40 & 23.18 \\
Lucerne & 157.15 & 108.84 & - & 124.94 \\
Other hay, forage and silage crops & 8.67 & 31.47 & 21.53 & 21.08 \\
Other dryland crops & 21.32 & 22.67 & 20.27 & 21.53 \\
Zone 2 (all dryland crops) & 29.13 & 33.34 & 58.00 & 39.18 \\
Wheat-fallow & 24.65 & 20.99 & 35.52 b & 26.19 \\
Other hay, forage and silage crops & 32.29 & 54.72 & 99.91 & 64.27 \\
Cotton & - & 112.15 & 112.32 & 112.25 \\
Other dryland crops & 52.86 & 48.04 & 63.07 & 53.78 \\
Zone 3 (all dryland crops) & 70.42 & 58.62 & 87.19 & 70.78 \\
Wheat-fallow & 48.53 & 33.76 & $63.48 \mathrm{~b}$ & 47.74 \\
Lucerne & 233.81 & 250.91 & 340.00 & 258.56 \\
Other hay, forage and silage crops & 48.59 & 68.11 & 65.72 & 57.60 \\
Cotton & 35.63 & 55.47 & 158.68 & 69.59 \\
Other dryland crops & 43.33 & 22.89 & $69.00^{\mathrm{b}}$ & 43.75 \\
\hline aThe crop diversity variable ranks producers based on percentage of cultivated acres in crops other \\
than wheat, lucerne or other hay and forage crops for the period 2002-2005. Low diversity = 0-10\% \\
(35 out of 141 producers); medium diversity = 11-30\% (67 producers); and high diversity = > 30\% of \\
cultivated acreage (39 producers). \\
bThe average for high-diversity operations was significantly greater than the average for medium- \\
diversity categories based on one-way analysis of variance and LSD post hoc comparisons $(P<0.05)$. \\
\end{tabular}

Evident in Table 6.5, lucerne and cotton are the most profitable crops on a per-acre basis. Lucerne, however, is typically maintained as a stand for 3-5 years (hence, lucerne is not typically rotated with winter wheat or other crops on an annual basis). While lucerne and cotton are the most profitable crops, these are grown in selected locations where they grow well and where there are established markets or processing facilities (cotton gins). Other hay, forage and silage crops are also presented separately in Table 6.5, because many producers have at least some cultivated acreage in these crops to provide food for livestock. Thus, these crops may or may not increase the overall crop diversity of a given farm operation.

The simplest (least diverse) dryland cropping system in the programme area is either continuously planted winter wheat or a wheat-fallow rotation. The crop diversity of farm operations is represented by three categories in Table 6.5, ranking operations as low, medium or high crop diversity. The least diverse farm operations had $10 \%$ or less of cultivated dryland acres in a crop other than wheat, fallow, lucerne, or other hay, forage, or silage crops. The most diverse had $30 \%$ or more of their 
cultivated dryland in some other crop. Crops rotated with winter wheat on an annual or semi-annual basis varied by project zone.

In Zone 1, 45 producers participating in the areawide programme collectively averaged about 55,000 acres (22,000 ha) of wheat and 53,000 acres (21,000 ha) of fallow per year, in the period 2002-2005. The three most common crops rotated annually or semi-annually with wheat and fallow were proso millet $(16,000$ acres (6400 ha)), sunflower (9000 acres (3600 ha)) and maize (5000 acres (2000 ha)). Dryland lucerne was produced by only three programme participants, with an average of only 86 acres ( $35 \mathrm{ha}$ ) annually; other hay, forage and silage crops, however, accounted for about 3000 acres (1200 ha) annually. The much larger acreage of wheat and fallow compared with the other crops is a reflection of the prevalence of the wheat-fallow dryland farming system in Zone 1 .

The figures in Table 6.5 do not indicate a profit advantage for more diversified farm operations in Zone 1. Overall net returns were slightly higher among the least diverse, US $\$ 24.58$, compared with US $\$ 22.15$ among the most diverse. Lucerne appears influential in this difference, but few operators (only three out of 45 producers) in Zone 1 had lucerne. Medium-diversity operators had the greatest returns from other hay, forage and silage crops, US $\$ 31.47$, while the low-diversity operators averaged much lower, at US $\$ 8.67$. Returns from other dryland crops were quite similar among all Zone 1 producers. None of the averages observed for Zone 1 were statistically significant based on one-way analyses of variance and LSD post hoc comparison tests.

The wheat-fallow system is as prevalent in Zone 2 as it is in Zone 1. In Zone 2, 42 producers in the areawide programme collectively averaged 63,000 acres (25,000 ha) of wheat and 40,000 acres (16,000 ha) of fallow annually during the period 2002-2005. Among the other dryland crops that were grown in annual or semi-annual rotations with winter wheat in Zone 2 were grain sorghum $(18,000$ acres (7200 ha)), cotton (3000 acres (1200 ha)), sunflower (1000 acres (400 ha)) and maize (840 acres (340 ha)). Hay, forage and silage crops accounted for about 2000 dryland acres (800 ha) among Zone 2 producers.

Table 6.5 does indicate higher average returns overall for high crop-diversity farm operations in Zone 2: the figure for high-diversity operations is US $\$ 58.00$, contrasted with US\$33.34 among medium-diversity operations and US\$29.13 among low-diversity operations. This result was partly due to significantly higher average returns from wheat and fallow acres among the higher-diversity operations. The average returns from wheat and fallow for high-diversity operations, US\$35.52, were significantly greater than the average for medium-diversity operations, US $\$ 20.99$ (based on one-way analysis of variance and LSD post hoc comparisons). However, the difference between high diversity, Us $\$ 35.52$, and low diversity, US\$24.65, was not statistically significant. This result was due to high variability in net returns among producers within both categories - high-diversity and low-diversity operations. Zone 2 medium-diversity operations averaged about the same return per acre for cotton, US $\$ 112.15$, as the high-diversity operations, US\$112.32, but none of the lowdiversity operations produced dryland cotton.

In Zone 3, continuous wheat (without a fallow period) is the norm due to higher rainfall as compared with the other two zones. Collectively, 54 producers in Zone 3 of the areawide programme averaged 70,000 acres (28,000 ha) of wheat annually and only 237 acres $(91 \mathrm{ha}$ ) of fallow. Leading crops grown in rotation with wheat 
among these producers were grain sorghum (7000 acres (2800 ha)), soybeans (4000 acres (1600 ha)), cotton (3000 acres (1200 ha)) and maize (3000 (1200 ha) acres). Lucerne (5000 acres (2000 ha)) and other hay, forage and silage crops (4000 acres (1600 ha)) also accounted for a substantial portion of dryland crop acreage among Zone 3 producers.

Continuous wheat production is known to exacerbate grassy weed problems, which is one probable reason that the more diversified operations in Zone 3 averaged significantly higher average returns from wheat: US\$63.48 per acre among high-diversity operations compared with US\$33.76 for medium-diversity operations. However, many low-diversity operations in Zone 3 also had above-average returns from wheat acres (group average $=\mathrm{US} \$ 70.42$ ), resulting in a non-significant difference in returns from wheat comparing low- and high-diversity operations in Zone 3.

The trend was comparable for other dryland crops, where high-diversity operations also averaged significantly higher returns (US\$69.00) compared with medium-diversity operations (US\$22.89), but not significantly higher than the average for low-diversity (US\$43.33) operations, again due to high within-group variability. The average returns from cotton for high-diversity operations appear advantageous (US\$158.68) compared with medium- (US\$55.47) and low-diversity (US\$35.63); however, only nine out of 54 producers (and only two high-diversity operators) grew cotton, resulting in high standard errors for the observed averages. Results observed for lucerne followed a similar pattern.

\section{Conclusions}

The AWPM producer group was diverse, in terms of production systems and geographic location. Within the group there will be significant differences in the level of adoption of each programme element and corresponding levels of success with the adopted elements.

As many have in the past, producers will probably adopt resistant cultivars as they are made available, although the initial use will be on a trial basis, as it is with most technology adoption by farmers. These initial trials will make it easy for the producers to evaluate and determine the compatibility with the individual farm characteristics and insect pressures. During the focus groups, producers mentioned the need for resistance to insects other than aphids. If resistant cultivars for other insects are made available, it can be assumed that producers will sow these varieties on a trial basis for evaluation. The location and regularity of aphid problems will be critical to the long-term and widespread adoption of resistant cultivars, both in the USA and in other areas of the world.

Development of simplified field scouting systems that are adaptable to different geographic locations and a variety of insect pests will have the potential for initial adoption, with increased use over time. Decreasing the complexity and the time requirements for field scouting has and will continue to enhance the acceptability of this technology. At the present time a simplified, quick field scouting process (Glance $' \mathcal{N}$ ' Go) is applicable only to greenbug management. A similar process would be widely accepted across the entire programme region if made available. This technology 
could also prove highly useful in other wheat-growing areas of the world, particularly in locations of smaller-acreage fields and farms.

The adoption of crop diversification will be more difficult to apply on a widespread basis in the arid environment of the US Great Plains. Regardless of where it occurs, crop diversification is complex because it involves broader changes in farm operation, goals, personal and financial characteristics of operators, and potential resistance from landlords and agricultural lenders. Crop selection encompasses personal, technical, financial and economic factors (Makeham and Malcolm, 1993; Corselius et al., 2003). Adoption of even relatively simple crop diversity can require changes in tillage system, marketing management and an investment in machinery to be successful. This limits the amount of trial adoption that producers are willing to entertain. Instead, farmers are more likely to undertake extensive reading and research before making the change to crop diversity and fewer tillage operations, then shift the entire farm to the new system.

In the short term there will be difficulties associated with this change, which will have the producer questioning the decision. This lack of observable results is a key challenge faced in the adoption of crop diversity on an areawide basis. Several cost-of-production analyses have pointed out the advantages, or at least a lack of disadvantages, to the adoption of crop diversity form and economic perspective. Delivery of this information in conjunction with information of the insect, weed and disease management benefits will be critical to the continued areawide adoption of crop diversity.

To date, the Cooperative Extension System has played the major role in the diffusion of IPM technologies for dryland winter wheat. Along with continued interaction with farm producers who are innovators and community leaders, USDA-ARS should continue to find ways to coordinate with CES research and extension professionals to achieve adoption of AWPM programme elements. CES agricultural extension agents/educators remain in the best position to act as change agents by determining the applicability of programme elements and information needs of producers in local areas. CES agents/educators already alert growers to potential aphid outbreaks through multiple communication channels: radio, newsletters, e-mail alerts and personal communication. They also already assist growers with cultivar selection, field scouting and crop diversification decisions. CES agents/educators could benefit from AWPM information technology (IT) advancements in their efforts to communicate effectively with producers. Thus, the research community can continue to provide technologies appropriate to producers by working through traditional cooperative extension channels.

\section{References}

Anderson, R.L, Bowman, R.A., Nielsen, D.C., Vigil, M.F., Aiken, R.M. and Benjamin, J.G. (1999) Alternative crop rotations for the central Great Plains. Journal of Production Agriculture 12, 95-99.

Baumgärtner, J., Getachew, T., Melaku, G., Sciarretta, A., Shifa, B. and Trematerra, P. (2003) Cases for adaptive ecological systems management. Redia LXXXVI, 165-172. 
Baumgärtner, J., Pala, A.O. and Trematerra, P. (2007) Sociology in integrated pest management. In: Koul, O. and Cuperus, G.W. (eds) Ecologically Based Integrated Pest Management. CAB International, Wallingford, UK, pp. 154-179.

Bechinski, E.J. (1994) Designing and delivering in-the-field scouting programmes. In: Pedigo, L.P. and Buntin, G.D. (eds) Handbook of Sampling Methods of Arthropods in Agriculture. CRC Press, Boca Raton, Florida, pp. 683-706.

Bennett, C.F. (1977) Analyzing Impacts of Extension Programs. Publication ESC-575, Extension Service, US Department of Agriculture, Washington, DC.

Buttel, F.H., Gillespie, G.W., Jr. and Power, A. (1990) Sociological aspects of agricultural sustainability in the United States: a New York case study. In: Edwards, C.A. (ed.) Sustainable Agricultural Systems. Soil and Water Conservation Society, Ankeny, Iowa, pp. 515-532.

Chandler, L.D. and Faust, R.M. (1998) Overview of areawide management of insects. Foumal of Agricultural Entomology 15, 319-325.

Corselius, K.L., Simmons, S.R. and Flora, C.B. (2003) Farmer perspectives on cropping systems diversification in northwestern Minnesota. Agriculture and Human Values, 20, $371-383$.

Coughenour, C.M. (2003) Innovating conservation agriculture: the case of no-till cropping. Rural Sociology 68, 278-304.

Coughenour, C.M. and Chamala, S. (2000) Conservation Tillage and Cropping Innovation: Constructing the New Culture of Agriculture. Iowa State University Press, Ames, Iowa.

Cuperus, G.W. and Berberet, R.C. (1994) Training specialists in sampling procedures. In: Pedigo, L.P. and Buntin, G.D. (eds) Handbook of Sampling Methods of Arthropods in Agriculture. CRC Press, Boca Raton, Florida, pp. 669-681.

Cuperus, G.W., Mulder, P.G. and Royer, T.A. (2000) Implementation of ecologically based IPM. In: Rechcigl, J.E. and Rechcigl, N.A. (eds) Insect Pest Management: Techniques of Environmental Protection. Lewis Publishers, Boca Raton, Florida, pp. 171-204.

Daugovish, O., Lyon, D.J. and Baltensperger, D.D. (1999) Cropping systems to control winter annual grasses in winter wheat (Triticum aestivum). Weed Technology 13, 120-126.

Dent, D. (1995) Programme planning and management. In: Dent, D. (ed.) Integrated Pest Management. Chapman \& Hall, London, pp. 120-151.

Dhuyvetter, K.C., Thompson, C.R., Norwood, G.A. and Halvorson, A.D. (1996) Economics of dryland cropping systems in the Great Plains: a review. Fournal of Production Agriculture 9, 216-222.

Elliott, N.C., Royer, T.A., Giles, K.L., Kindler, S.D., Porter, D.R., Elliott, D.T. and Waits, D.A. (2004) A web-based decision support system for managing greenbugs in wheat. Crop Management (online) doi:10.1094/CM-2004- 1006- 01-MG.

Faust, R. (2001) Forum - invasive species and areawide pest management: what we have learned. Agricultural Research (http://www.ars.usda.gov/is/AR/archive/nov01/form1101. $\mathrm{htm})$.

Fliegel, F.C. with Korsching, P.F. (2001) Diffusion Research in Rural Sociology: the Record and Prospects for the Future. Social Ecology Press, Middleton, Wisconsin.

Fuchs, T.W. (2007) Diffusion of IPM programmes in commercial agriculture: concepts and constraints. In: Koul, O. and Cuperus, G.W. (eds) Ecologically Based Integrated Pest Management. CAB International, Wallingford, UK, pp. 432-444.

Kaan, D.A., O’Brien, D.M., Burgener, P.A., Peterson, G.A. and Westfall, D.G. (2002) An Economic Evaluation of Alternative Crop Rotations Compared to Wheat-Fallow in North-eastern Colorado. Colorado State University, Agricultural Experiment Station, Technical Bulletin TB02-1.

Keenan, S.P., Giles, K.L., Burgener, P.A., Christian, D.A. and Elliott, N.C. (2007a) Collaborating with wheat producers in demonstrating areawide integrated pest management. Journal of Extension 45 (http://www.joe.org/joe/2007february/a7.shtml). 
Keenan, S.P., Giles, K.L., Elliott, N.C., Royer, T.A., Porter, D.R., Burgener, P.A., and Christian, D.A. (2007b) Grower perspectives on areawide wheat integrated pest management in the southern US Great Plains. In: Koul, O. and Cuperus, G.W. (eds) Ecologically Based Integrated Pest Management. GAB International, Wallingford, UK, pp. 289-314.

Kipling, E.F. (1980) Areawide pest suppression and other innovative concepts to cope with our more important insect pest problems. In: Minutes of the 54th Annual Meeting of the National Plant Board, Sacramento, California, pp. 68-97.

Kogan, M. (1998) Integrated pest management: historical perspectives and contemporary developments. Annual Review of Entomology 43, 243-270.

Kogan, M., Croft, B.A. and Sutherst, R.F. (1999) Applications of ecology for integrated pest management. In: Huffaker, C.B. and Gutierrez, A.P. (eds) Ecological Entomology. John Wiley \& Sons, New York, pp. 681-728.

Leeuwis, C. and van den Ban, A. (2004) Communication for Rural Innovation: Rethinking Agricultural Extension. 3rd edn., Blackwell Science, Oxford, UK.

Makeham, J.P. and Malcolm, L.R. (1993) The Farming Game Now. Cambridge University Press, Cambridge, UK.

North Central Rural Sociology Committee (1955) How Farm People Accept New Ideas. North Central Regional Publication No. 1 of the Agricultural Extension Services (Reprinted in 1981 as Special Report No. 15, Iowa State University Cooperative Extension (http://www. soc.iastate.edu/extension/publications/SP15.pdf, accessed 26 March 2007)).

Nowak, P., Padgett, S. and Hoban, T.J. (1996) Practical considerations in assessing barriers to IPM adoption. Proceedings of the Third National IPM Symposium/Workshop. US Department of Agriculture, Economic Research Service, MP-1542, Washington, DC.

Petrzelka, P., Padgitt, S. and Connelly, K. (1997) Teaching old dogs survival tricks: a case study in promoting integrated crop management. Foumal of Production Agriculture 10, 596-602.

Ridgley, A. and Brush, S.B. (1992) Social factors and selective technology adoption: the case of integrated pest management. Human Organization, 51, 367-378.

Rogers, E.M. (2003) Diffusion of Innovations 5th edn., The Free Press, New York.

Rogers, E.M. with Shoemaker, F.F. (1971) Communication of Innovations: a Cross-cultural Approach. The Free Press, New York.

Royer, T.A., Giles, K.L. and Elliott, N.C. (2005a) Glance ' $n$ Go Sampling for Greenbugs in Winter Wheat. Spring edn., Oklahoma Cooperative Extension Service, Oklahoma State University Extension Facts, L-306, Stillwater, Oklahoma.

Royer, T.A., Giles, K.L. and Elliott, N.C. (2005b) Glance 'n Go Sampling for Greenbugs in Winter Wheat. Fall edition, Oklahoma Cooperative Extension Service, Oklahoma State University Extension Facts, L-307, Stillwater, Oklahoma.

Ryan, B. and Gross, N.C. (1943) The diffusion of hybrid seed corn in two Iowa communities. Rural Sociology 8, 15-24. 